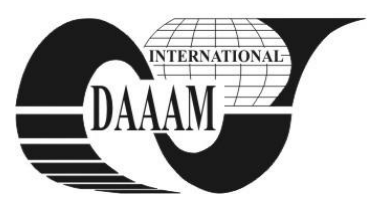

Annals of DAAAM for 2011 \& Proceedings of the 22nd International DAAAM Symposium, Volume 22, No. 1, ISSN 1726-9679 ISBN 978-3-901509-83-4, Editor B. Katalinic, Published by DAAAM International, Vienna, Austria, EU, 2011 Make Harmony between Technology and Nature, and Your Mind will Fly Free as a Bird Annals \& Proceedings of DAAAM International 2011

\title{
REMOTE LABORATORY FOR AUTOMATION SYSTEM DESIGN
}

\author{
ZENZEROVIC, P[aolo]; MACUKA, D[aniel] \& KRISKOVIC, D[omagoj]
}

\begin{abstract}
This paper presents the concept of a new laboratory educational platform for engineering students in the field of industrial automation. System functions are: specification of all components of automation system, their interconnections and the development, improvement, upload and testing of its software. All assumptions and solutions have been confirmed by computer simulation and partial hardware implementation. The web application implemented for remote laboratory management has also been presented.
\end{abstract}

Key words: remote laboratory, distance learning, educational technology, engineering education, microcontroller system

\section{INTRODUCTION}

One of the main megatrends in modern technology is computer integration. Computer integration started in 1970's and will finish about the year 2030. There are many different faces of realization of computer integration such as internet, computer aided technology, communications, mobile communications, smart technology, and many others.

Computer integration is deseminating and infiltrating in many engineering fields including automation. Computer integration in automation gives us huge possibilities of acting at a distance. Modern industrial automation is primary based on microcontrollers and programmable logic controllers. Computer integration opens the possibilities of remote usage of microcontrollers and programmable logic controllers.

During the development, in the past, this access was focused on the software solutions (Sousa et al., 2010; GarciaZubia et al., 2010; Ferrarer-Simon et al., 2009). Modern approach also includes an extension on the access to hardware by using Soft-wiring approach between controllers and their peripherals.

In the frame of this project concept of remote design of control systems based on microcontrollers and programmable logic controllers is developed.

The target group of users of this system are engineering students in the field of automation.

\section{PROPOSED CONCEPT}

The user of the system has the following possibilities:

- $\quad$ specification of control units

- $\quad$ specification of peripheral devices

- $\quad$ specification of controlled system

- specification of interconnection between all components

- developing, uploading testing and improvement of software

This system includes the following modules: web server, system controller (microcontroller and programmable logic controller), general usage measuring modules, basic microcontroller modules, basic programmable logic controller modules, Soft-wiring sytem, LED matrix, seven segment displays, seven segment displays in multiplexed mode of operation, textual display, remote button module and specialized measuring modules.

\subsection{Control units}

The laboratory platform offers two types of system controllers: microcontrollers and programmable logic controllers. The end user may use any number of the two mentioned controller types.

\subsection{Peripheral devices}

Peripheral devices include typically used optoelectronic components for graphical human machine interfacing. All the peripheral devices can be viewed by web camera stream or by accessing data from specialized measuring modules. The end user can also remotely affect the digital state of the declared input pins of any controller by using a specialized remote button/switch module.

\subsection{Controlled system}

The controlled system state can be simulated by LED matrix or outputs from the controller can be directed to the electropneumatic components available in the laboratory platform. The laboratory platform gives the possibility to control any peripheral device by any controller. It also enables the user to use multiple controllers for more complex applications. For example: the programable logic controller for the control of the electropneumatic components and the microcontroller to build the user interface and monitoring system.

\subsection{The "Soft-wiring" system}

This system was designed with the purpose of giving the remote laboratory user the possibility to remotely change the interconnections between the used controller and its peripherals (Zenzerović \& Sučić, 2010). This allows the end user to learn hardware design of digital systems The main concept of such a system is shown in figure 1 .

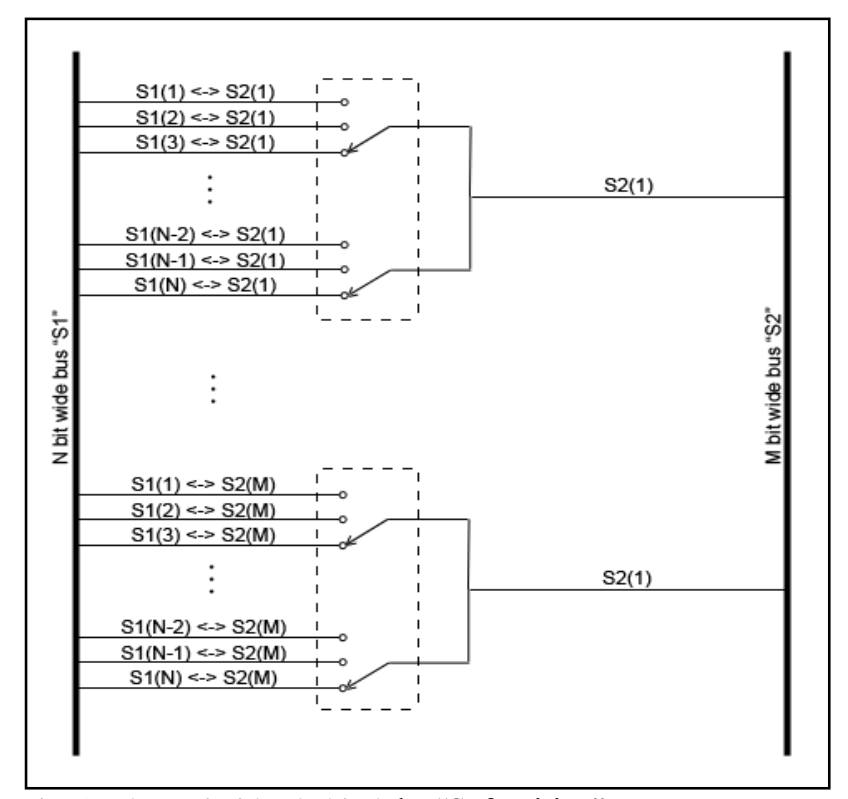

Fig. 1. The main idea behind the "Soft-wiring" system 


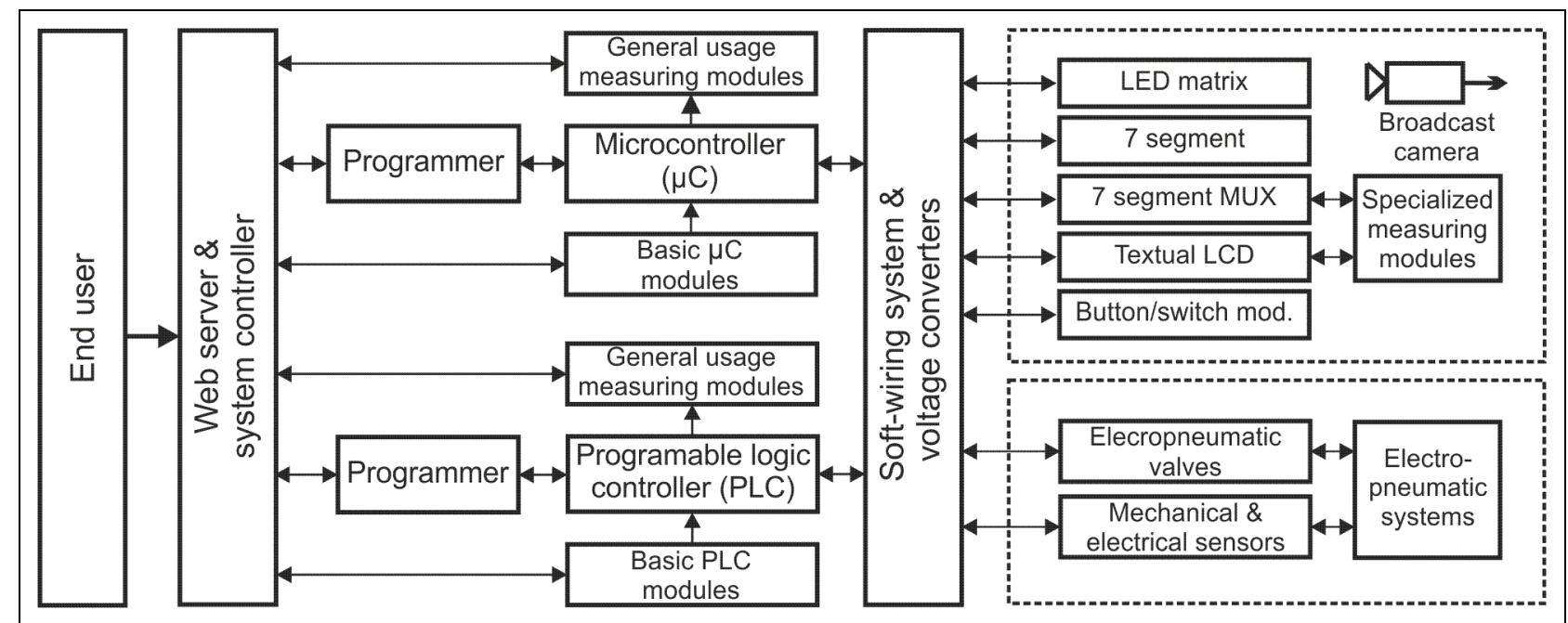

Fig. 2. Block diagram of proposed remote laboratory system

This system is used to interconnect any/all pins of the first bus ( $\mathrm{N}$ bit wide bus "S1" shown on the left of Fig. 1.) to any/all pins of the second bus (M bit wide bus "S2" shown on the right of Fig. 2.). This system can be implemented in more ways, depending on the electrical specifications of the busses. The options are relays, multiplexers and demultiplexers, analog multiplexers or FPGA devices. The first version of the system based only on microcontrollers and their typical peripheral devices adopts analog multiplexers to interconnect the two busses. This solution was tested and gave positive results. The disadvantage of this solution is the number of integrated circuits needed to interconnect two 32 bit wide busses, and the area needed on PCB boards. The proposed solution uses FPGA devices which minimizes the overall cost and area needed for PCB design. It also gives the possibility for easy system improvements by reprogramming the FPGA firmware.

\subsection{Web application}

The web application created to manage all the remote laboratory resources and users is hosted on the web server (Krišković, 2010). The web application controls the programmers for the user accessible microcontroller and programmable logic controller. The user can select which controllers will be used in the project (microcontroller, programmable logic controller or both), and easily interconnect their pins to the peripheral modules, by using the implemented graphical assistant.

Both the controllers are connected to general usage measuring modules which serve as a multichannel digital oscilloscope. Those modules can measure the states of all the digital input/output pins of the controllers. The measured data can be displayed as virtual light emitting diodes in the web application (see fig. 3.).

Except the mentioned measuring modules the end user can see the responces of the system by viewing the feedback video streamed from the installed web cameras.

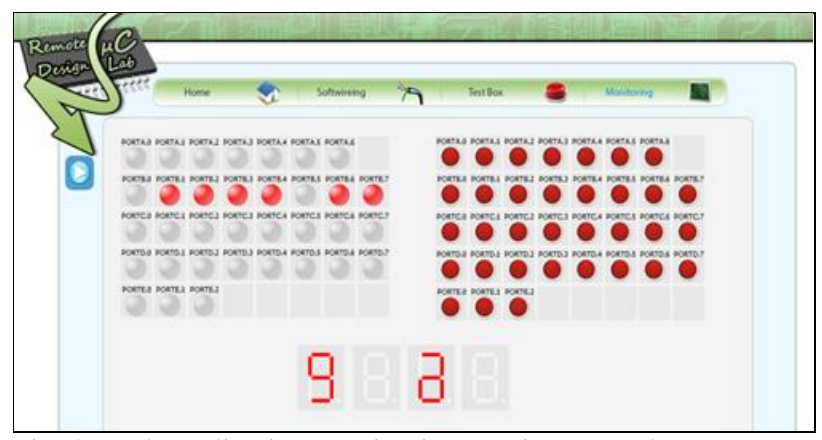

Fig. 3. Web application running in experiment mode

\section{CONCLUSION}

Progress on the work on this project is promising. Realization of this project at institutions for technical education opens basically new possibilities and quality of education for the next generation of engineers in industrial automation.

\section{FUTURE WORK}

All described system components except electropneumatic components have been implemented in hardware. Those modules passed the proof of concept stage and will be included in the platform in the near future.

\section{ACKNOWLEDGEMENTS}

The authors want to express special thanks to the Faculty of Engineering, University of Rijeka and the CEEPUS (CIII-HR0108) network in this project.

\section{REFERENCES}

Ferrater-Simon, C., Molas-Balada, L., Gomis-Bellmunt, O., Lorenzo-Martinez, N., Bayo-Puxan, O. \& VillafafilaRobles, R. (2009). A Remote Laboratory Platform for Electrical Drive Control Using Programmable Logic Controllers, IEEE Transactions on Education, ISSN: 00189359, pp. 425-435, IEEE Educational Society

García-Zubia, J., Angulo, I., Hernandez, U., Castro, M., Sancristobal, E., Orduña, P.; Irurzun, J. \& de Garibay, J.R. (2010). Easily Integrable platform for the deployment of a Remote Laboratory for microcontrollers, Proceedings on IEEE Education Engineering conference, ISBN: 978-14244-6568-2, pp. 327-334, IEEE Educational Society

Krišković, D. (2010). Remote laboratory for the design of microcontroller systems: web application and communication protocol development, Final thesis, Faculty of Engineering, University of Rijeka (in Croatian)

Sousa, N., Alves, G. R. \& Gericota, M.G. (2010). An integrated reusable remote laboratory to complement electronics teaching, IEEE Transactions on Learning technology, Vol. 3, Issue 3, ISSN: 1939 1982, Nejdl, W. (Ed.), IEEE Education Society

Zenzerović, P. \& Sučić, V. (2011). Remote laboratory for microcontroller systems design, 2011 Proceedings of the 34th International Convention MIPRO, ISBN: 978-1-45770996-8, pp. 1685-1688, Croatian Society for Information and Communication Technology, Electronics and Microelectronics - MIPRO 